\title{
Destination image influencing the travel behavior amidst the COVID-19 pandemic in the case of Batangas province
}

\author{
Barlan, Christine Mae M. \\ Lyceum of the Philippines University Batangas, Philippines (cmbarlan@lpubatangas.edu.ph) \\ Borbon, Noelah Mae D. \\ Lyceum of the Philippines University Batangas, Philippines (nmdborbon@lpubatangas.edu.ph)
}

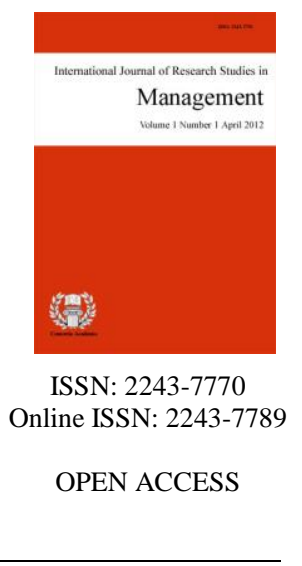

Received: 9 November 2021

\section{Abstract}

The study's goal is to offer a non-biased thesis about the relationship between the destination's image and the tourist's travel behavior. To help tourists decide whether or not to visit the province's destinations, this information is available. Respondents were asked about their demographic profile of respondents in terms of age, sex, civil status, occupation, highest educational attainment, and psychographic profile prior to taking the survey. Additionally, in light of the COVID-19 epidemic, the study attempts to assessed how visitors' perceptions of their location influence their travel plans. The researcher used a survey questionnaire among 385 tourists. It was found out that Travel behavior of the tourist in terms of Outcome Quality, indicates bringing family or friends in a vacation is pleasurable. Visitors who have visited Batangas Province at least twice in the last year are the subjects of this research. The result showed the Gen $\mathrm{Z}$ or age 25 years old below have greater assessment about trust, healthcare system, and crisis management. This study found a strong correlation between a tourist destination's image and its visitors' travel habits. Results show that the image of a location is essential to a visitor's travel behavior. The duty of the destination is to provide the best available services while simultaneously preserving the health and safety of visitors.

Keywords: environmental quality, healthcare system, intention to visit, tourist satisfaction, trust 


\section{Destination image influencing the travel behavior amidst the COVID-19 pandemic in the case of Batangas province}

\section{Introduction}

Tourism supports millions of jobs around the globe. This COVID-19 virus stopped the tourism industry and contributed fear and anxiety to the tourist. This research is a study finding the relationship of pandemic in the travel behavior of the tourist in relationship to the destination image of Batangas province. Tourist destination image is resilient at times of adversity, a fact that must give some comfort to those who have worked hard to develop the destination image that represents an underlying assurance of experience at a site. The preservation of stability and a point of connection should thus be enhanced via emotional interactions (Nadeau et al., 2021).

Now that COVID-19 has disrupted life's regular cycle, tourist spots in Batangas have embraced the new health and safety standards that will allow visitors to come without fear of catching a contagious disease. The destination must rebuild the trust of the tourists, create a crisis management plan, comply with the healthcare system of the government, and increase solidarity in the community. A number of COVID-19 research have tried to distinguish the major elements that influence post-pandemic travel plans, such as individuals' perceptions of intra-pandemic risk (Li et al., 2020; Rasoolimanesh et al., 2021; Neuburger \& Egger, 2020; Sánchez- Cañizares et al., 2020); representations of health risks at a destination (Bhati et al., 2020; Rastegar et al., 2021; Han et al., 2021).

Thus, Nazir et al. (2021) found that a person's goal image and behavioral intention are negatively impacted by their perception of risk and belief in constraint. Behavior might be influenced positively by a pleasant impression of the destination image. A moderating effect of goal image was also seen in the study's interactions between behavioral intention and perceptions of danger and limitation. Destinations may find it difficult to overcome restrictions at times, thus managers should provide value-added services as alternatives. Destination managers should advertise their locations as well, since a positive perception of a destination may help overcome any obstacles and hazards. The COVID-19 caused tourists to be anxious and fearful when traveling and leaving their homes. This pandemic, however, will not deter tourists from seeking the freedom of relaxation and entertainment that a vacation provides. Travelers who intend to visit a destination will always be around. Travel enthusiasts will find a way to pursue travel and will support destinations through positive reviews and vlogs to encourage future travelers. According to Ivanova and Ivanov (2020) Tourists will travel inside the country, by vehicle, and with their families in the post-pandemic world. Sanitation and a solid health-care system are the most crucial factors to consider while choosing a location.

When the Taal volcanic eruption occurred before COVID-19 broke out, the researcher was there to see this sad chain of events. According to a CNN Philippines report (2020) Hundreds of people were forced to abandon their homes when Taal Volcano erupted on January 12, devastating livelihoods and property, causing thousands to flee their homes, and proclaiming a state of emergency among 15 towns and cities throughout Batangas and neighboring Cavite provinces. There was also estimated damage of P86.5 million in the 14-kilometer zone and losses of P123.2 million according to the Provincial Tourism and Cultural Affairs Office's preliminary report. Batangas and Cavite, two southern Philippine provinces, were still recovering from the explosion of Taal Volcano in January when the coronavirus hit. The tourism destination is trying to standstill amidst crises. Governor Hermilando Mandanas of Batangas stated that the province had barely regained 50\% of the total damage from the Taal eruption (Ozaeta, 2020).

Moreover, COVID-19 is an invisible enemy and a very contagious disease. There is a need for the industry to stop the tourist operations of museums, churches, and beaches in the province. This has had yet another negative impact on the province's and the country's tourist economy. It was in late 2020 when the government 
permitted the destinations to operate again, but with a precautionary measure and strict guidelines for health protocols provided by the Inter-Agency Task Force (IATF) and the Department of Health (DOH).

This research determined the negative effects of the COVID-19 pandemic on the tourist's desire to visit Batangas province. Based on the findings of this study, the perception of a place and the likelihood of tourists visiting that location are intimately linked. Improved tourist satisfaction was achieved as a result of this research. In this way, Batangas Province was presented to tourists as a potential vacation destination. Another goal is to help those working in the tourist business and future scholars.

\subsection{Objective of the Study}

This research assessed the destination image influencing the travel behavior amidst the COVID-19 pandemic in Batangas Province. Specifically, it sought to present the demographic profile of the respondents in terms of age, sex, civil status, occupation, highest educational attainment, second, it determined tourists' destination image in response to COVID-19 pandemic in terms of: trust, crisis management, healthcare system, and solidarity; third, this determined the travel behavior of the tourist in terms of: outcome quality, physical environment quality, tourist satisfaction, place identity, place dependence, intention to recommend and intention to visit; fourth, it tested the significant difference among the responses when grouped according to the profile variables. Moreover, it tested the significant relationship between destination image and travel behavior. Lastly, it proposed a strategic plan as an input for continuous improvement plan based on the result of the study.

\section{Methodology}

\subsection{Research Design}

The researcher used a survey questionnaire to conduct quantitative research. Comparative analysis may be used to do this kind of research on a single target audience group, or it can be used to examine many groups at once. This kind of study requires a random selection of participants. Since a large number of respondents will be randomly selected, a researcher will be able to ensure the validity of the data.

\subsection{Participant of the Study}

The respondents of this study are tourists who traveled within Batangas Province for no less than 2 times for 2019 to present. Rao soft sample size calculator was used in to find out the appropriate sample where the researcher randomly selected in the 8,046,920-population based from PTCAO tourist arrivals in 2019 the calculated sample size was 385 tourists with the confidence level of 95\% who came from 25-57 years old, male and female, single and married, employed and unemployed with different educational attainment.

\subsection{Data Collection Instrument}

Part one of the instrument presented the profile of the respondents. Part two of the instrument determined the Tourist's Destination Image that is based on the Modified questionnaire from the study of Rasoolimanesh et al. (2021) while part three of the questionnaire is Adapted from the study of Madridano (2021) which determined the Tourist behavioral intention in visiting attractions in Batangas Province. The instrument has undergone into a content validation and pilot testing. The instrument's reliability was checked using the Cronbach Alpha Reliability Coefficient Test. 15 items for Tourist's Destination Image (0.972) and 21 items for Tourist's Behavior Intention (0.973) have an excellent value of Cronbach's alpha higher than 0.90. Under the tourist's destination image which includes trust, crisis management, health care system, and solidarity, the general interpretation on all the indicators are excellent with an average of 0.972 Cronbach's Alpha which has a total of fifteen indicators. Among all the sub-variables under tourist's destination image, trust has the highest Cronbach's Alpha with 0.960 while crisis management is the lowest with 0.920 . The general interpretation of tourist's behavior intention is 
excellent with a 0.973 Cronbach's Alpha. With all the sub variables, intention to visit has the highest Cronbach's Alpha with 0.963 interpreted as excellent followed by environment quality with 0.950 and place identity with 0.945 both interpreted as excellent. The intention to recommend has the lowest Cronbach's Alpha with 0.847 interpreted as good followed by tourist satisfaction with 0.876 Cronbach's Alpha also interpreted as good.

\subsection{Data Gathering Procedure}

The researcher used modified survey questionnaire and sent it via online google form and social media like Facebook messenger was used to disseminate the instrument to the participants of the research. Some of the respondents sent the survey screenshot to the researcher as a proof of participation. The data gathering took a month. After the researcher had reached the 385 participants, the instrument was immediately passed to the statistician for the validation and interpretation of the result.

\subsection{Data Analysis}

This study used descriptive statistics comprising frequency distribution to know the profile of respondents in terms of age, sex, civil status, occupation, highest educational attainment, and frequency of visit; meanwhile, the weighted mean is to determine the tourist's destination image of the province in response to COVID-19 in terms of trust, crisis management, healthcare system, and solidarity and to determine travel behavior of the tourist in terms of outcome quality, physical environment quality, tourist satisfaction, place identity, place dependence, intention to recommend and intention to visit. The given scale was used to interpret the result of the data gathered: $3.50-4.49=$ Strongly Agree; 2.50 - $3.49=$ Agree; $1.50-2.49=$ Disagree; $1.00-1.49=$ Strongly Disagree. Likewise, Spearman rho was used to test the significant relationship between the two variables. In addition, all data was treated using a statistical software known as PASW version 26 to further interpret the result of the study using an alpha level of 0.05 .

\subsection{Ethical Consideration}

The researcher attached a data privacy act agreement in the google form survey before proceeding to the actual questionnaire which explains its purpose and guidelines for the participants to be well-informed that their opinions and statements would be treated strongly confidential, and this study would impose no harm to them. The research study remained private throughout the study and the researcher used its real name in the research consent letter. The identity of the participants was not be revealed except the residents of the barangay where the attraction is located. The researcher followed the ethical standards in order for the public to believe and support the study.

\section{Results and Discussion}

\section{Table 1}

Percentage Distribution of the Respondents Profile

\begin{tabular}{lcc}
\multicolumn{1}{c}{ Age } & Frequency & Percentage (\%) \\
\hline 25 years and below (Gen Z) & 151 & 38.60 \\
26-41 years old (Gen Y) & 153 & 39.10 \\
42-56 years old (Gen X) & 64 & 16.40 \\
57 years old and above (Baby Boomers) & 23 & 5.90 \\
\hline Sex & & \\
\hline Male & 176 & 45.00 \\
Female & 215 & 55.00 \\
\hline Civil Status & & \\
\hline Single & 168 & 43.00 \\
Married & 223 & 57.00 \\
\hline
\end{tabular}


Table 1 ... continued

\begin{tabular}{lcc}
\hline Occupation & & \\
\hline Employed & 192 & 49.10 \\
Self Employed & 47 & 12.00 \\
Student & 126 & 32.20 \\
Unemployed & 26 & 6.60 \\
\hline Highest Educational Attainment & & \\
\hline High School Graduate & 103 & 26.30 \\
Vocational Graduate & 14 & 3.60 \\
College Graduate & 184 & 47.10 \\
Post Graduate & 90 & 23.00 \\
\hline
\end{tabular}

Table 1 present the demographic profile of the respondents in terms of age, sex, civil status, occupation, and highest educational attainment. Majority of the respondents are 26-41 yrs. old with 39.10 percent followed by 25 years old and below with 38.60 percent. This means that most of the tourists are in Gen Y or Millennials. Being adventurous and eager to explore, they tend to travel more. Millennials want to customize personal experience for themselves, not simply typical vacations. Millennials are looking for more than just a place to stay. When they travel, they want to have a full experience and to be able to immerse themselves in the local culture.

Most of the respondents are female with 215 or 55 percent while 176 respondents or 45 percent are male. This means that female tend to travel more. Women manage to travel alone in this present time to make quality time for herself, to meet new friends and to explore new places. Women most likely to eliminate stress by traveling by her own and embracing self-love and self-care to her being. Some women will trade marriage and children to pursue a career. This shows that a career woman earns enough money and have the means to travel. Almost all the respondents are married with 223 or 57 percent while 168 respondents or 43 percent are single. This represents most of the tourists are married. Couples, mostly newlyweds, love to spend their honeymoon together in a romantic beaches and other relaxing destinations. Their relationship is being strengthen through experiencing different places. The couple who loves to travel discover the strength and weaknesses of each partner. The more the couple will travel, the more they can understand the attitude of each other.

Nearly all the respondents are employed with 192 or 49.10 percent followed by student with 126 respondents or 32.20 percent. This implies that majority of the tourists are employed. This indicates that employed individuals are traveling whether on business or leisure purposes. They also need vacation to escape from their usual work routine. Also, traveling can be rewarding and boost the morale of the employees. Many of the respondents are tertiary graduate with 184 or 47.10 percent and followed by high school graduate with 103 respondents or 26.30 percent. This indicates that greater part of the tourists are college graduates. This implies that educational attainment can influence the decision-making of the tourist to choose a destination. Before "settling down" to work, many graduates have the desire to travel and explore.

\section{Table 2}

Assessment on Tourists' Destination Image

\begin{tabular}{lccc}
\hline \multicolumn{1}{c}{ Indicators } & Weighted Mean & Verbal Interpretation & $\mathrm{R}$ \\
\hline Trust & 3.42 & Agree & 2 \\
Crisis Management & 3.29 & Agree & 3 \\
Health Care System & 3.26 & Agree & 4 \\
Solidarity & 3.44 & Agree & 1 \\
\hline Composite Mean & 3.35 & Agree & \\
\hline Legend $: 3.50-4.00=$ Strongly Agree $; 2.50-3.49=$ Agree; $1.50-2.49=$ Disagree; $1.00-1.49=$ Strongly Disagree
\end{tabular}

Table 2 shows the assessment on Tourists' Destination Image with a composite mean of 3.35 and interpreted verbally as agree. Generally, solidarity comes out on top, followed by trust, with mean of 3.44 and 3.42 respectively. Majority of Batangas residents have faith in the government's information and communication regarding the infection and fatality rates of COVID-19. Thus, it can be deduced that people in Batangas support one another both financially and non-financially to lessen the psychological and emotional effects of this crisis. Anxieties for Batangas residents grew during the COVID-19 incident. All of Batangas' people helped and cared 
for one another.

The findings of Bertog and Koos (2021) show that social disparities that are produced by the socioeconomic situations of donors and volunteers influence the patterns of help. Socioeconomic status has the potential to influence one's willingness to help others by influencing one's resources, networks, and attitudes. Existing research indicates that there are significant variations in assisting others based on socioeconomic status. Individuals with better incomes, more education, and higher employment positions are more likely to volunteer and donate than those with fewer of these advantages. Emotional solidarity, on the other hand, was positively connected with support for tourism, according to Joo et al. (2021), whereas felt risk was negatively correlated. An additional mediator between perceived risk and tourist support was revealed to be emotional solidarity. Concerns about one's health and one's faith in government have a modest interaction in Schneider et al. (2021), which predicts support for development aid. People who have a high level of trust in the government are more likely to support development aid when they are concerned about the loss of friends or family members.

Among all the indicators, crisis management ranks third with a mean of 3.29 agree and last on the rank is health care system with 3.26 interpreted as agree. Despite that, the respondents believe in the successful handling of supply chain risk and disruption (food and medical shortages) in Batangas. Also, the Batangas authorities' quick and early detection and treatment of Covid-19. And, of course, the robust and prompt response to COVID-19 in Batangas. However, there is room for development for Batangas' healthcare system to be dependable and resilient. In addition, tracking of people exposed to COVID-19 in Batangas must been improved.

This is supported by the study of Biana (2020), the nation's capital's healthcare system has reached a bending point. "The healthcare system has been overloaded" as a result of the "apparently unending number of patients trooping" to hospitals for emergency treatment and admittance.

Additionally, the COVID-19 vaccine has been developed and is currently being taken by many people as a response to this pandemic. As a result, the Department of Health (DOH) - CALABARZON (Cavite, Laguna; Batangas; Rizal; and Quezon) has once again urged residents to get their Covid-19 injections to protect themselves against the virus' various variants, particularly the Delta variant, which is the most dangerous because it is twice as contagious and spreads more quickly than a normal virus (GOVPH, 2021). This immunization effort relies heavily on social media to get the word out to the general public. According to the research of de Vero et al. (2021), technology can be used in epidemiology to help communities by building a basic monitoring system in these difficult times. The Philippines can benefit from this Honduran breakthrough by enhancing the country's ability to respond to public health crises.

\section{Table3}

Assessment on Travel Behavior of the Tourist

\begin{tabular}{lccc}
\hline Indicators & Weighted Mean & Verbal Interpretation & $\mathrm{R}$ \\
\hline Outcome Quality & 3.52 & Strongly Agree & 5.5 \\
Environmental Quality & 3.52 & Strongly Agree & 5.5 \\
Tourist Satisfaction & 3.56 & Strongly Agree & 3.5 \\
Place Identity & 3.56 & Strongly Agree & 3.5 \\
Place Dependence & 3.48 & Agree & 7 \\
Intention To Recommend & 3.58 & Strongly Agree & 2 \\
Intention To Visit & 3.61 & Strongly Agree & 1 \\
\hline Composite Mean & 3.55 & Strongly Agree \\
\hline Legend: $3.50-4.00=$ Strongly Agree $; 2.50-3.49=$ Agree; $1.50-2.49=$ Disagree; $1.00-1.49=$ Strongly Disagree
\end{tabular}

Table 3 presents the assessment on travel behavior of the tourist. A composite mean of 3.55 indicates that the respondents strongly agreed in general. The indicator that ranks first is the intention to visit with a mean of 3.61 followed by intention to recommend with 3.58 and tie on the third rank, are tourist satisfaction and place identity with a mean of 3.56, hence, all interpreted as strongly agree. This shows that tourists are very willing to stay and visit Batangas. They also believe in the enthusiasm of the business operators and local government in handling the safety and health protocols of individual. This suggests that Batangas' tourism spots are interesting to visitors.

18 Consortia Academia Publishing (A Partner of Tourism Educators and Movers of the Philippines) 
This shows that visitors intend to visit, and this desire will lead to a commitment to visit the location if the destination satisfies the tourist's expectations. Tourist satisfaction will lead to a desire to suggest the location since they have received outstanding quality services at the destination.

With these claims in mind, Hamilo Coast says Batangas is a site of breathtaking seascapes, wonderful diving places, rich farms and majestic mountains, as well as clean and peaceful rivers that flow into a beautiful lake with a volcano in the distance. As a result of all of this, it should come as no surprise that tourists and locals alike love returning to the city. There seems to be a system in place to reduce the danger of bringing in cases and spreading the disease inside a community (Philippine Travel Advisory, 2021). Undersecretary Bengzon Jr. highlighted that, previous to the pandemic, there were around 110 million annual domestic travels producing five times the revenue of inbound visitors, which Villegas (2021) underscored.

With a weighted mean of 3.48 and a verbal meaning of agree, indicator number five, which measures location reliance, is tied for last place with outcome quality and environmental quality. This means that the physical environment of the institution or destination has to be upgraded. The area's ecologically friendly settings may entice visitors. The threat of the COVID-19 illness necessitates additional precautions in the physical environment. This implies that while they're on vacation, people want a wider variety of goods and services to choose from. They are open to visiting Batangas on a budget over the holidays. They think Batangas is a fantastic place to go on vacation, but they're hoping for something really unique.

According to the findings of a study conducted by Mirzaei et al. (2021), travelers' worry about health and safety have grown sharply in recent years. Cleaning and disinfection of tourist facilities has grown from a hygienic concern to a motivating factor. Travelers avoid long-distance trips because they believe they put their health at danger, so they opt for shorter excursions instead. It has also been said that the effects of tourist attractions were generally recognized in socio-cultural, environmental, and economic aspects; responses were consistent across each profile; and an action plan was offered. This was also mentioned by Magboo et al. (2019), that should be additional activities and excursions offered at the tourist site in order to keep it fresh and interesting for visitors.

\section{Table 4}

Difference Responses Between the Tourists' Destination Image When Grouped According to Profile

\begin{tabular}{llll}
\hline Age & $\mathrm{U} / \lambda^{2} \mathrm{c}$ & $\mathrm{p}$-value & Interpretation \\
\hline Trust & 8.484 & 0.037 & Significant \\
Crisis Management & 7.44 & 0.059 & Not Significant \\
Health Care System & 12.642 & 0.005 & Significant \\
Solidarity & 3.073 & 0.380 & Not Significant \\
\hline Sex & & & Not Significant \\
\hline Trust & 17531.5 & 0.191 & Not Significant \\
Crisis Management & 17602.5 & 0.215 & Not Significant \\
Health Care System & 18132.5 & 0.462 & Not Significant \\
Solidarity & 17739.5 & 0.269 & \\
\hline Civil Status & & & Not Significant \\
\hline Trust & 17596.5 & 0.282 & Not Significant \\
Crisis Management & 17986 & 0.481 & Not Significant \\
Health Care System & 17652 & 0.310 & Not Significant \\
Solidarity & 18039.5 & 0.514 & Significant \\
\hline Occupation & & & Significant \\
\hline Trust & 7.743 & 0.052 & Not Significant \\
Crisis Management & 8.558 & 0.036 & \\
Health Care System & 11.045 & 0.011 & Not Significant \\
Solidarity & 4.074 & 0.254 & Not Significant \\
\hline Highest Educational Attainment & & & Not Significant \\
\hline Trust & 1.691 & 0.639 & Not Significant \\
Crisis Management & 0.609 & 0.894 & \\
Health Care System & 2.068 & 0.558 & 0.631 \\
Solidarity & 1.725 & &
\end{tabular}


Table 4 shows the comparison of responses on tourist destination image when grouped according to demographic profile. It was observed that there was a significant difference on trust $(\mathrm{p}=0.037)$ and health care system $(\mathrm{p}=0.005)$ when grouped according to age. This was observed since the obtained $\mathrm{p}$-values were less than 0.05 alpha level. This means that the answers differ statistically and based on the post hoc test conducted, it was learned out that respondents whose age bracket are 25 years old and below has greater assessment on the above-mentioned variables. This means that Generation $\mathrm{Z}$ needs trustworthy government that provides consistent updates for the health and safety of everyone. This group of people are young yet wise in choosing places to travel. This bracket is especially concerned about the recent COVID-19 developments because this illness has also affected their usual lives. Health and safety are the top priority of everyone right now and tourists are only trusting reliable source before making any travel decisions.

Generation Z (those born between 1995 and 2010) is the most stressed-out of all the modern named generations, according to Stone (2021). Businesses have a rare chance to understand their concerns, build relationships with this group, and maybe gain customer loyalty by appealing to their need for security and trust in an uncertain world. However, their devotion and confidence must be gained. Thus, customer satisfaction is measured using a variety of criteria, including trustworthiness, responsiveness, and interaction (Ponterfract, 2018). Furthermore, Gen $Z$ is less willing to believe anything just because it is available on the internet. In addition, there was also a significant difference on crisis management $(p=0.036)$ and health care system $(p=$ 0.011) because the computed p-value were less than the alpha level, thus the responses were observed on students.

This means that students are also affected in the crisis management set by the government. They are also vulnerable in the COVID-19 disease. This generation $\mathrm{Z}$ most of the time using social medias and this influence their perception about the destinations. Batangas province is active on social medias as they update everyone even the students about the health and safety protocols set by the government. This is supported by the study of Schuckert, (2016), stating that many individuals get their information from many internet outlets, including social media. Moreover, according to Leung et al. (2019) tourism experts have been studying the influence of social media on travel decisions. It seems that most research have concentrated on how social media affects people's intentions, rather than how it affects their actual behavior, according to a recent literature review. Given that travel services are intangible and perceived risk is high throughout the trip decision-making process, social media has influence on customer behavior which has gained considerable attention in the tourism and travel industry.

Table 5

Difference Responses Between the Travel Behavior of the Tourist When Grouped According to Profile

\begin{tabular}{llll}
\hline \multicolumn{1}{c}{ Age } & \multicolumn{1}{c}{ r-value } & p-value & \multicolumn{1}{c}{ Interpretation } \\
\hline Outcome Quality & 6.031 & 0.11 & Not Significant \\
Environmental Quality & 8.366 & 0.039 & Significant \\
Tourist Satisfaction & 7.72 & 0.052 & Not Significant \\
Place Identity & 4.501 & 0.212 & Not Significant \\
Place Dependence & 0.903 & 0.825 & Not Significant \\
Intention To Recommend & 2.997 & 0.392 & Not Significant \\
Intention To Visit & 3.471 & 0.325 & Not Significant \\
\hline Sex & & & Not Significant \\
\hline Outcome Quality & 17434 & 0.158 & Not Significant \\
Environmental Quality & 17371.5 & 0.133 & Not Significant \\
Tourist Satisfaction & 17841 & 0.289 & Not Significant \\
Place Identity & 18813 & 0.917 & Not Significant \\
Place Dependence & 16947 & 0.058 & Not Significant \\
Intention To Recommend & 18410.5 & 0.614 & Not Significant \\
Intention To Visit & 18855.5 & 0.948 & \\
\hline
\end{tabular}


Table 5 ... continued

\begin{tabular}{llll}
\hline Civil Status & & & \\
\hline Outcome Quality & 18653.5 & 0.940 & Not Significant \\
Environmental Quality & 18469.5 & 0.798 & Not Significant \\
Tourist Satisfaction & 18382.5 & 0.730 & Not Significant \\
Place Identity & 18435.5 & 0.771 & Not Significant \\
Place Dependence & 17599 & 0.274 & Not Significant \\
Intention To Recommend & 18229.5 & 0.617 & Not Significant \\
Intention To Visit & 18351.5 & 0.699 & Significant \\
\hline Occupation & & & Not Significant \\
\hline Outcome Quality & 10.796 & 0.013 & Not Significant \\
Environmental Quality & 4.977 & 0.174 & Not Significant \\
Tourist Satisfaction & 7.758 & 0.051 & Not Significant \\
Place Identity & 4.388 & 0.222 & Not Significant \\
Place Dependence & 4.922 & 0.178 & Not Significant \\
Intention To Recommend & 5.035 & 0.169 & Not Significant \\
Intention To Visit & 6.842 & 0.077 & Not Significant \\
\hline Highest Educational Attainment & & & Not Significant \\
\hline Outcome Quality & 0.234 & 0.972 & Not Significant \\
Environmental Quality & 1.318 & 0.725 & Significant \\
Tourist Satisfaction & 1.487 & 0.685 & Not Significant \\
Place Identity & 0.692 & 0.875 & Not Significant \\
Place Dependence & 8.623 & 0.035 & \\
Intention To Recommend & 2.023 & 0.568 & 0.607 \\
Intention To Visit & 1.838 & &
\end{tabular}

Legend: Significant at p-value $<0.05$

Table 5 displays the comparison of responses on tourist behavior when grouped according to demographic profile. It was noted that there was a significant difference on environmental quality when grouped according to age. since the obtained p-value of 0.039 was less than 0.05 alpha level. This means that the responses differ significantly and based on the post hoc test conducted, it was found out that respondents whose age bracket are 25 years old and below has greater assessment on environmental quality.

This means that this generation is concerned on the physical qualities of the destination. Clean and safe environment are required to appeal the taste of this bracket. Moreover, this generation appreciates a destination with good environment. There is a lot of overlap in the travel characteristics of Millennials and GenZers: they are socially and ecologically concerned, they want a mobile-first strategy, and they seek real local experiences Hotel companies must have strong, active social media presences for visitors to interact with at any time since Generation $\mathrm{Z}$ is constantly online and comfortable with social media. Keeping your social media profiles up-to-date, posting often, and interacting with others on a variety of platforms all fall under the umbrella of a successful social media marketing strategy.

According to de Wilde (2020), Generation Z grew up in an era of unprecedented knowledge about human behavior, personal health, technology, and the environment's impact on humans. Travel habits of Generation $\mathrm{Z}$ are shaped by factors such as globalization; the 2008 financial crisis; terrorism; climate change; and technology. The good news is that, according to Telus International (2021), travel and hospitality companies don't have to reinvent themselves to meet the needs of Millennials and Generation Z. These people spend up to 10 hrs. a day staring at screens, and many specialists believe it's not an addiction but rather an extension of one's personality (Williams, 2019).

In addition, there was also a significant difference on outcome quality $(\mathrm{p}=0.013)$ because the computed p-value was less than the alpha level, thus the responses vary, and this was observed on students. This generation is always utilizing social media, and always expects something from the destinations they see on online. This group is well-connected to the internet, and they want to share the quality of their trip with their friends. Moreover, Gen $\mathrm{Z}$ is the first generation to be dubbed digital natives, assuring their early adoption of technology. Thus, the usage of gadgets is prevalent among this generation, creating expectations about inexpensive, seamless access at home and when traveling (de Wilde, 2020). They have higher expectations than earlier generations and 
are ready to pay more money to go on the trip of their dreams. Similarly, according to Williams (2019), millions of Gen Zers have evolved sophisticated ways for filtering out unnecessary information. To reach them in a meaningful way, you must go where they hang out (hint: it's online). Focusing on direct, personalized message that stresses benefits for them, and using feedback and interaction is an advantage. Earning immediate credibility by demonstrating to your Gen $\mathrm{Z}$ guests to understand social media by including it into their trip is needed.

Lastly, the responses also vary on place dependence since the resulted p-value of 0.035 was less than the prescribed alpha level. From the pairwise comparison, it was found out that those who obtained college degree have greater assessment on place dependence. Most of the people in this bracket are working and they have the means to spend holidays in a vacation. Company incentives are sometimes in a form of staycation or vacation and most of the employees are happily enjoying this perk. Going in a trip are much more fun with colleagues. This is supported by the study of Ni et al. (2017) research, when graduates go on a working holiday, they are impacted by "internal personal thinking" and "external driving factors."

\section{Table 6}

Relationship Between the Tourists' Destination Image and Travel Behavior of the Tourist

\begin{tabular}{|c|c|c|c|}
\hline Trust & r-value & p-value & Interpretation \\
\hline Outcome Quality & $.700 * *$ & 0.000 & Highly Significant \\
\hline Environmental Quality & $.683 * *$ & 0.000 & Highly Significant \\
\hline Tourist Satisfaction & $.688 * *$ & 0.000 & Highly Significant \\
\hline Place Identity & $.647 * *$ & 0.000 & Highly Significant \\
\hline Place Dependence & $.627 * *$ & 0.000 & Highly Significant \\
\hline Intention To Recommend & $.675 * *$ & 0.000 & Highly Significant \\
\hline Intention To Visit & $.563 * *$ & 0.000 & Highly Significant \\
\hline \multicolumn{4}{|l|}{ Crisis Management } \\
\hline Outcome Quality & $.661 * *$ & 0.000 & Highly Significant \\
\hline Environmental Quality & $.612 * *$ & 0.000 & Highly Significant \\
\hline Tourist Satisfaction & $.594 * *$ & 0.000 & Highly Significant \\
\hline Place Identity & $.598 * *$ & 0.000 & Highly Significant \\
\hline Place Dependence & $.614 * *$ & 0.000 & Highly Significant \\
\hline Intention To Recommend & $.572 * *$ & 0.000 & Highly Significant \\
\hline Intention To Visit & $.497 * *$ & 0.000 & Highly Significant \\
\hline \multicolumn{4}{|l|}{ Health Care } \\
\hline Outcome Quality & $.712 * *$ & 0.000 & Highly Significant \\
\hline Environmental Quality & $.647 * *$ & 0.000 & Highly Significant \\
\hline Tourist Satisfaction & $.616 * *$ & 0.000 & Highly Significant \\
\hline Place Identity & $.602 * *$ & 0.000 & Highly Significant \\
\hline Place Dependence & $.604 * *$ & 0.000 & Highly Significant \\
\hline Intention To Recommend & $.577 * *$ & 0.000 & Highly Significant \\
\hline Intention To Visit & $.496 * *$ & 0.000 & Highly Significant \\
\hline \multicolumn{4}{|l|}{ Solidarity } \\
\hline Outcome Quality & $.703 * *$ & 0.000 & Highly Significant \\
\hline Environmental Quality & $.695 * *$ & 0.000 & Highly Significant \\
\hline Tourist Satisfaction & $.698 * *$ & 0.000 & Highly Significant \\
\hline Place Identity & $.679 * *$ & 0.000 & Highly Significant \\
\hline Place Dependence & $.671 * *$ & 0.000 & Highly Significant \\
\hline Intention To Recommend & $.682 * *$ & 0.000 & Highly Significant \\
\hline Intention To Visit & $.631 * *$ & 0.000 & Highly Significant \\
\hline
\end{tabular}

Legend: Significant at p-value $<0.01$

Table 6 shows the association between tourist destination image and travel behavior of the tourist. It was observed that the computed rho-values indicates a strong direct correlation, and the resulted p-values are less than the alpha level of 0.01 . This means that a significant relationship exists and implies that the better the tourist destination image and more positive the travel behavior of the tourist.

Tourist trust, crisis management, healthcare system and solidarity are highly significant in relationship to the outcome quality, environmental quality, tourist satisfaction, place identity, place dependence, Intention to recommend and intention to visit. The quality of the outcome will be determined by the image of the tourist destination. Tourist sites in Batangas are relatively accessible, however due to the virus, many visitors avoid 

going on vacation. Tourism in Batangas has been severely impacted, and the government is working to mitigate the effects of the pandemic. The government permits tourists to travel, but they must adhere to health and safety standards.

This is reinforced by the findings of Kuer et al. (2021), which highlight the steps necessary to create resilience as well as the responsibilities and interventions that may aid in the restoration of tourism. Incorporation of policymakers' viewpoints and dissemination of policy making and strategy reformulation information to tourism organizations are common practices. Governments and destinations may benefit from this information in deciding how to respond to the COVID-19 pandemic, focusing on both the good and negative outcomes. Tourists place a high value on environmental quality because they expect a location to be clean and well-maintained. Eco-friendly tourist locations can boost tourism by providing a pleasant atmosphere for visitors. Most of the responders are employees who require a break from their jobs. This group of persons yearns for a setting that is dissimilar to their working environment. Furthermore, according to Castro (2017), A favorable tourist experience, met expectations, repeat visits, and a recommendation of a site are all linked to good infrastructure, care, cleanliness, and availability of parking.

Thus, tourist satisfaction is achieved by exceeding tourist expectations in the destination. The tourist's pleasure is determined by the experience they have at the place. This means that the destination should be aware of the tourist's expectations in order to determine the products and services that are required. Hence, the accommodation that a tourist destination must be appealing to the customer's preference. This is supported by the study of Ye et al. (2019), study results show that the moderating impact of tourist expectations occurs in the lodging sector but not in the attraction sector. According to the findings, visitors who have greater expectations for lodging service are more sensitive to service performance.

Tourism relies heavily on the notion of "place identity," which is a social construct based on observable physical features of a location. As a result, a place must provide exceptional services to meet the expectations of visitors and make them feel particularly connected and valued. According to Pan et al. (2021), travelers would also compare their earlier destination photos after they arrived at the local tourism. They will be more satisfied with the local service quality if it fits the prior impression.

The tourist intention to recommend Batangas is crucial since its attractions are exceptional. Most responders use modern channels such as social media to promote Batangas tourism and aid in its recovery. Most people are now online, which would encourage friends and family to visit Batangas after the COVID-19 crisis. Moreover, when consumers are given user-generated content (UGC) that is related to tourism locations, they construct expectations about the area by putting their trust in the material collected, according to Narangajavana et al. (2017). In order to encourage more user-generated content (UGC), tourism businesses should maintain their quality standards. This will foster more trust in social media and raise visitors' expectations.

The respondent's intention to visit is quite important. Tourists' intention to revisit after COVID-19 is feasible in the near future. They are eager to visit Batangas since the region has easily accessible locations with notable beaches to enjoy. Furthermore, according to results from the Loi et al. (2017) research, the picture of a place increases a person's desire to return. According to the findings, destination marketers should aim for a high-quality tourist shuttle service in terms of service, efficiency, punctuality, and safety. A visitor's decision to visit a tourist destination is influenced by the place's image, according to this study. It is the responsibility of the destination to provide the finest services available in order to safeguard the health and safety of tourists. Huete-Alcocer et al. (2019) affirm that although a variety of factors may influence the success of this kind of tourism, it is essential that all measures and strategies used be focused on ensuring the pleasure of all visitors. The findings show that the tourist's image of this location is more influenced by their emotional response than their rational one. 
Table 7

Action Plan to Improve Tourist Destination Image and Travel Behavior

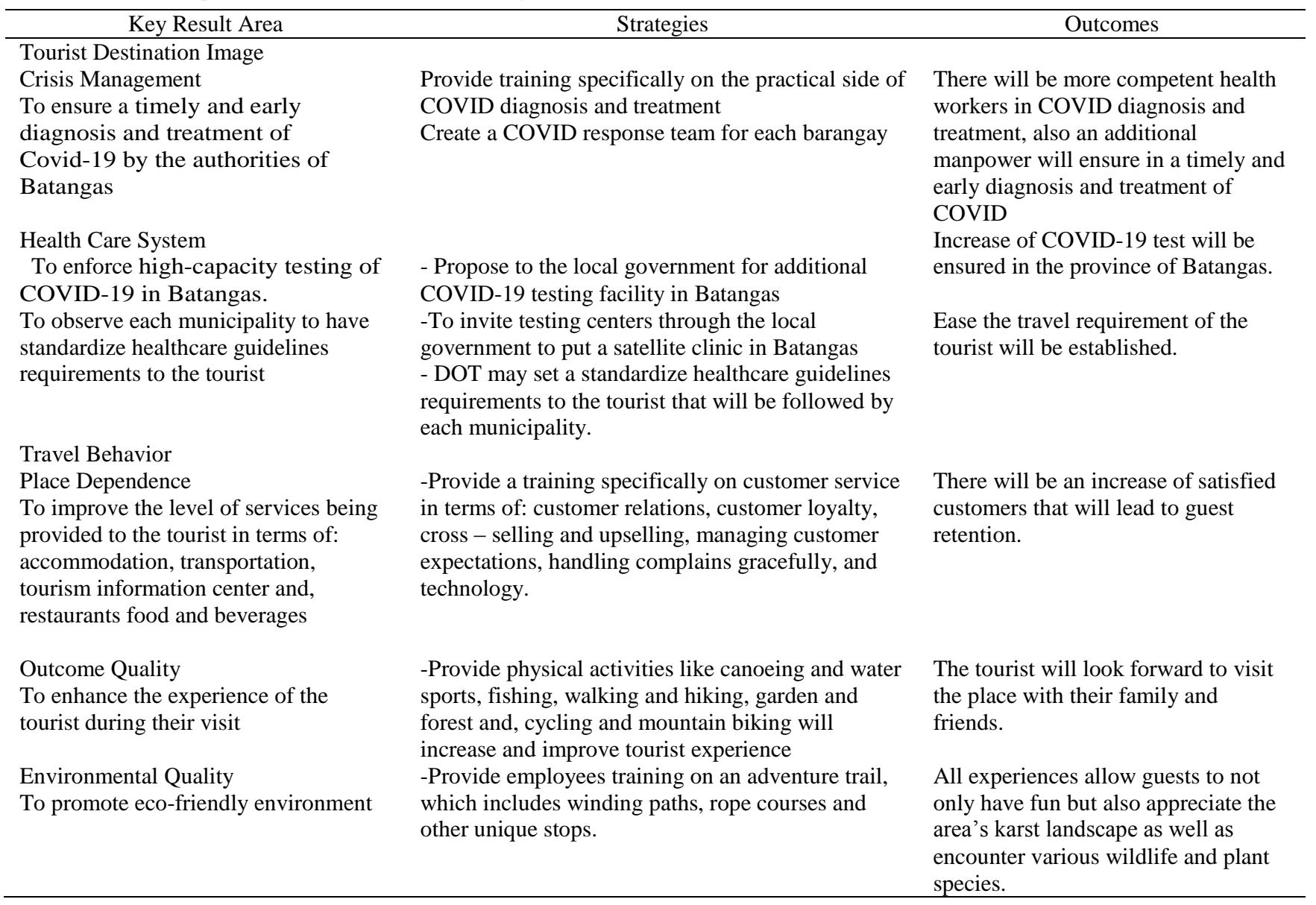

\section{Conclusion and Recommendation}

Most of the respondents are 26-41 years old (Gen Y), female, married, employed with bachelor's degree. In terms of Tourists' destination image in terms of Trust, the information provided by the government are highly trusted since it is coming from a reliable source. Thus, the communication released by the government of Batangas greatly influence on the tourist destination image. In terms of Crisis Management. It only shows that Batangas Government has a good management strategy in terms securing necessary supply in case of the occurrence of crisis. In terms, of healthcare system, Local Government Unit in Batangas are equipped with reliable public health workers. In terms, of Solidarity, most of the Filipino are generous and caring. Some create an event like community pantries to aid hunger during the pandemic this kind of gesture showed the native products offered by the province such as kapeng barako and rice cakes.

Travel behavior of the tourist in terms of Outcome Quality, indicates bringing family or friends in a vacation is pleasurable. In terms of physical environment quality, it shows that the province of Batangas maintain most of its attraction to be impressive in the eyes of the tourists. In terms, of tourist satisfaction, this indicates that tourists had faith in the destination's services. The more satisfied the visitor is, the more likely they are to return and have good memories of the location. In terms, of place identity, this means that the scenic view of Taal volcano is one of the attractions that Batangas province made special to the tourist. Further are the relaxing beaches and diving sites that are remarkable to visit. And religious sites that offer soul searching and peace to the tourist. In terms of Place dependence, many destinations in Batangas are budget-friendly even in holiday season. Most of the tourists want relaxation on a holiday on a budget. In terms of intention to recommend, Batangas is something to talk about for the people who loves to travel and relax. Tourist attractions are also remarkable that 
the visitors are compelled to say good things about it even after the pandemic. Last, in terms of Intention to visit, tourists still consider Batangas as a great escapade. It is convenient to travel to Batangas because it is accessible via Star toll way from Manila and it is a gateway to the Port. Most of the municipalities in Batangas are low-risk in the COVID-19 disease this means more destinations are open to the public.

The result showed the Gen $\mathrm{Z}$ or age 25 years old below have greater assessment about trust, healthcare system, and crisis management when group according to profile. Moreover, this generation also has a significant response in terms of, environmental quality, outcome quality, and place dependence. Significant relationship exists and indicates that the better the tourist destination image and more positive the travel behavior of the tourist. This shows that tourist destination image is the key to the satisfaction of the travel behavior of the tourist. The destination's role is to provide the best services by ensuring the health and safety of the tourists. Key areas to improve in the tourist destination image are crisis management and health care system. These two variables are being addressed by ensuring a timely and early diagnosis and treatment of Covid-19 by the authorities of Batangas and enforce high-capacity testing of COVID-19 in Batangas. In terms of Travel behavior, the place dependence, outcome quality and environmental quality are the areas that need improvement. All these variables are connected to the customer's satisfaction and customer's expectation to the destination.

Local Government unit, may provide current information about the health and safety protocols of tourist destination in Batangas. Tourism Office, may validate the safety compliance of the tourism business operators in response to COVID-19. Tourism Business, may offer extraordinary amenities and services such as child daycare, bike racks, fitness facility, covered parking, mobile check-in, room amenities: in-room tablets, free Wi-Fi internet access and enthusiast and hobbyist tech to the visitors and consider the behavioral intentions of Gen $\mathrm{Z}$ and Millennials intention to visit a destination. Travel Agency, may make personalize tour packages based on the generation preferences to attract the traveler and engage them to participate in meaningful activities by providing them a map to go along with their tour so they can feel independent. Beaches and resort owners, may encourage the tourist to stay in a vacation by providing free WIFI, healthy breakfast, ample wall outlets, complimentary toiletries with hair styling tools, laundry services, crib and cots for children, pet-friendly rooms, business facilities and flexible checkout, as they follow the health and safety protocols and ensure to them a COVID-free facility. Future researcher, may perform comparable research with various factors such as tourist travel behavior in the post-pandemic, importance of fully vaccinated employees, staff and tourist to the destination image and local government unit safety and security measures implemented in Batangas Province.

\section{References}

Bertogg, A., \& Koos, S. (2021). Socio-economic position and local solidarity in times of crisis. The COVID-19 pandemic and the emergence of informal helping arrangements in Germany. Research in Social Stratification and Mobility, 74, 100612. https://doi.org/10.1016/j.rssm.2021.100612

Bhati, A. S., Mohammadi, Z., Agarwal, M., Kamble, Z., \& Donough-Tan, G. (2020). Motivating or manipulating: the influence of health-protective behaviour and media engagement on post-COVID-19 travel. Current Issues in Tourism, 24(15), 2088-2092. https://doi.org/10.1080/13683500.2020.1819970

Biana, H. T., \& Joaquin, J. J. B. (2020). COVID-19: The need to heed distress calls of healthcare workers. Journal of Public Health, 42(4), 853-854. https://doi.org/10.1093/pubmed/fdaa145

Castro, J. C., Quisimalin, M., de Pablos, C., Gancino, V., \& Jerez, J. (2017). Tourism marketing: Measuring tourist satisfaction. Journal of Service Science and Management, 10(03), 280-308. https://doi.org/10.4236/jssm.2017.103023

CNN Philippines. (2020, May 1). Re: Batangas hopeful tourism will flourish again after COVID-19 pandemic, Taal Volcano eruption. CNN. https://www.cnn.ph/news/2020/5/1/batangas-tourism-after-covid-19-taal-volcano-eruption.html

de Vero, M. K. B., Gozum, I. E. A., \& Melad, A. M. (2021). Prevention and planning as important factors in ensuring public health in the Philippines during the COVID-19 pandemic. Journal of Public Health, 43(2), e358-e359. https://doi.org/10.1093/pubmed/fdab058 
De Wilde, P. (2020). Study on generation z travellers. European Travel Commission. https://etc-corporate.org/uploads/2020/07/2020_ETC-Study-Generation-Z-Travellers.pdf

GOVPH. (2021, October 11). Prevent Covid-19 Variants, Get Vaccinated- Doh Calabarzon. Govph. https://ro4a.doh.gov.ph/

Han, Q., Zheng, B., Cristea, M., Agostini, M., Bélanger, J. J., Gützkow, B., Kreienkamp, J., \& Leander, N. P. (2021). Trust in government regarding COVID-19 and its associations with preventive health behaviour and prosocial behaviour during the pandemic: a cross-sectional and longitudinal study. Psychological Medicine, 1-11. https://doi.org/10.1017/s0033291721001306

Huete-Alcocer, N., Martinez-Ruiz, M. P., López-Ruiz, V. R., \& Izquiedo-Yusta, A. (2019). Archeological Tourist Destination Image Formation: Influence of Information Sources on the Cognitive, Affective and Unique Image. Frontiers in Psychology, 10. https://doi.org/10.3389/fpsyg.2019.02382

Ivanova, M., Ivanov, I. K., \& Ivanov, S. (2020). Travel behaviour after the pandemic: the case of Bulgaria. Anatolia, 32(1), 1-11. https://doi.org/10.1080/13032917.2020.1818267

Joo, D., Xu, W., Lee, J., Lee, C. K., \& Woosnam, K. M. (2021). Residents' perceived risk, emotional solidarity, and support for tourism amidst the COVID-19 pandemic. Journal of Destination Marketing \& Management, 19, 100553. https://doi.org/10.1016/j.jdmm.2021.100553

Leung, X. Y., Sun, J., \& Bai, B. (2019). Thematic framework of social media research: state of the art. Tourism Review, 74(3), 517-531. https://doi.org/10.1108/tr-05-2018-0058

Li, J., Nguyen, T. H. H., \& Coca-Stefaniak, J. A. (2021). Coronavirus impacts on post-pandemic planned travel behaviours. Annals of Tourism Research, 86, 102964. https://doi.org/10.1016/j.annals.2020.102964

Loi, L. T. I., So, A. S. I., Lo, I. S., \& Fong, L. H. N. (2017). Does the quality of tourist shuttles influence revisit intention through destination image and satisfaction? The case of Macao. Journal of Hospitality and Tourism Management, 32, 115-123. https://doi.org/10.1016/j.jhtm.2017.06.002

Madridano, P. G. V. (2021). Tourist behavioral intention in visiting attractions in Quezon Province. International Journal of Research Studies in Management, 9(1). https://doi.org/10.5861/ijrsm.2021.7708

Magboo, N. M. C., Blay, M. G., Balbastro, L. C., Landicho, M. S. R., Marasiga, E. H., Villasenor, A. M. F., \& Felicen, S. (2019). Impacts of Tourist Attraction in the Community of one City in the Philippines. Asia Pacific Journal of Academic Research in Business Administration, 5(1), 63-69.

Mirzaei, R., Sadin, M., \& Pedram, M. (2021). Tourism and COVID-19: changes in travel patterns and tourists' behavior in Iran. Journal of Tourism Futures, 2055-5911. https://doi.org/10.1108/JTF-01-2021-0017

Nadeau, J., Wardley, L. J., \& Rajabi, E. (2021). Tourism destination image resiliency during a pandemic as portrayed through emotions on Twitter. Tourism and Hospitality Research, https://doi.org/10.1177/14673584211038317

Narangajavana, Y., Callarisa Fiol, L. J., Moliner Tena, M. N., Rodríguez Artola, R. M., \& Sánchez García, J. (2017). The influence of social media in creating expectations. An empirical study for a tourist destination. Annals of Tourism Research, 65, 60-70. https://doi.org/10.1016/j.annals.2017.05.002

Neuburger, L., \& Egger, R. (2020). Travel risk perception and travel behaviour during the COVID-19 pandemic 2020: a case study of the DACH region. Current Issues in Tourism, 24(7), 1003-1016. https://doi.org/10.1080/13683500.2020.1803807

Ni, C. C., Tsao, C. Y., \& Wang, Y. H. (2018). The International Decision-Making and Travel Behavior of Graduates Participating in Working Holiday. Mobilities, Tourism and Travel Behavior - Contexts and Boundaries. Published. https://doi.org/10.5772/intechopen.70331

Ozaeta, T.G. (2020, February 29). Re: Batangas suffers P123 million in tourism losses due to Taal eruption. Rappler.com. https://www.rappler.com/nation/batangas-tourism-losses-taal-eruption

Pan, S., Chang, C. W., \& Zhu, Z. (2021). A Study of the Influence of Tourists' Destination Image and Perceived Service Quality on Their Behavioral Intention. Open Journal of Applied Sciences, 11(05), 585-595. https://doi.org/10.4236/ojapps.2021.115042

Philippine Travel Advisory. (2021, October 15). Have a safe trip Pinas. Philippine Travel Advisory. URL: https://philippines.travel/safetrip/batangas\#safetyprotocols

Ponterfract, D. (2018, June 3). Millennials And Gen Z Have Lost Trust and Loyalty with Business. Forbes. URL.

26 Consortia Academia Publishing (A Partner of Tourism Educators and Movers of the Philippines) 
Destination image influencing travel behavior amidst the COVID-19 pandemic in the case of Batangas province https://www.forbes.com/sites/danpontefract/2018/06/03/millennials-and-gen-z-have-lost-trust-and-loyal ty-with-business/?sh=3cd9640b6145

Rasoolimanesh, S., Seyfi, S., Rastegar, R., \& Hall, C. (2021). Destination image during the COVID-19 pandemic and future travel behavior: The moderating role of past experience. Journal of Destination Marketing \& Management, 21, 100620. https://doi.org/10.1016/j.jdmm.2021.100620

Rastegar, R., Seyfi, S., \& Rasoolimanesh, S. M. (2021). How COVID-19 case fatality rates have shaped perceptions and travel intention? Journal of Hospitality and Tourism Management, 47, 353-364. https://doi.org/10.1016/j.jhtm.2021.04.006

Sánchez-Cañizares, S. M., Cabeza-Ramírez, L. J., Muñoz-Fernández, G., \& Fuentes-García, F. J. (2020). Impact of the perceived risk from Covid-19 on intention to travel. Current Issues in Tourism, 24(7), 970-984. https://doi.org/10.1080/13683500.2020.1829571

Schneider, S. H., Eger, J., Bruder, M., Faust, J., \& Wieler, L. H. (2021). Does the COVID-19 pandemic threaten global solidarity? Evidence from Germany. World Development, 140, 105356. https://doi.org/10.1016/j.worlddev.2020.105356

Schuckert, M., Liu, X., \& Law, R. (2015). Insights into Suspicious Online Ratings: Direct Evidence from TripAdvisor. Asia Pacific Journal of Tourism Research, 21(3), 259-272. https://doi.org/10.1080/10941665.2015.1029954

Stone, M. (2021, May 18). Gen-Z: They Crave Stability and Trust, So Give It To Them. Forbes. https://www.forbes.com/sites/michaelstone/2021/05/18/gen-z-they-crave-stability-and-trust-so-give-it-t o-them/?sh=26d5c0f4594a

Telus International. (2021, June 3). How Generation $\mathrm{Z}$ is changing, and challenging, the future of travel. Telus International. https://www.telusinternational.com/articles/generation-z-future-of-travel

Villegas, B.M. (2021, October 5). The recovery of domestic tourism. Manila Bulletin. https://mb.com.ph/2021/10/05/the-recovery-of-domestic-tourism/

Williams, C. (2019, June 26). Generation Z: What Do They Want from their Hotel Stay Experience? HVS. https://www.hvs.com/article/8534/generation-z-what-do-they-want-from-their-hotel-stay/

Ye, R., \& Titheridge, H. (2017). Satisfaction with the commute: The role of travel mode choice, built environment and attitudes. Transportation Research Part D: Transport and Environment, 52, 535-547. https://doi.org/10.1016/j.trd.2016.06.011 
Barlan, C. M. M., \& Borbon, N. M. D.

28 Consortia Academia Publishing (A Partner of Tourism Educators and Movers of the Philippines) 